\title{
Spectrophotometric and Potentiometric Methods for the Determination of Cefprozil, Dropropizine and Tizanidine Hydrochloride in Pharmaceutical Preparations
}

\author{
F.M. Abdel-Gawad ${ }^{\#}$, C.S. Mostafa ${ }^{*}$, S.M. Abdel-Hamid and \\ N.A. Abbas \\ National Organization for Drug Control and Research, P.O. \\ Box 29, Giza, and *irls College, Al-Azher University, Cairo, \\ Egypt.
}

\begin{abstract}
T WO SIMPLE, accurate spectrophotometric and potentiometric methods were developed for the determination of cefprozil, dropropizine and tizanidine hydrochloride in their pharmaceutical preparations. The spectrophotometric method is based on the selective oxidation of cefprozil or tizanidine with $\mathrm{N}$-bromosuccinimide in an alkaline medium to give an intense yellow product with a maximum absorption at 396 or $384 \mathrm{~nm}$, respectively. The reaction conditions were studied and optimized. The reaction obeyed Beer's law over the concentration range 5-40 and $10-80 \mu \mathrm{g} \mathrm{ml}^{-1}$ for cefprozil and tizanidine hydrochloride, respectively. The potentiometric method involves the direct titration of cefprozil and dropropizine with $\mathrm{N}$ bromosuccinimide in sulphuric acid medium and the end point is determined potentiometrically using platinum electrode. Cefprozil and dropropizine can be determined quantitatively in the concentration range of $0.13-1.30$ and $0.118-1.180 \mathrm{mg}$ with recovery values of 98.46100.77 and $99.58-100.85 \%$ and relative standard deviations $0.39-0.54$ and $0.52-0.87 \%$ for cefprozil and dropropizine, respectively. The proposed methods are applied for the determination of these drugs in pure forms and in pharmaceutical preparations.
\end{abstract}

Keywords: Cefprozil, Dropropizine, Tizanidine hydrochloride, NBromosuccinimide, Spectrophotometry and Potentiometry

Cefprozil, (6R,7R)-7- [(R)-2- amino-2- (p-hydroxyphenyl) acetamido] -8- oxo-3propenyl-5-thia-1-azabicyclo[4.2.0]oct-2-ene-2-carboxylic acid (Scheme 1) is a semisynthetic oral second generation cephalosporin consists of 90:10 Z/E isomeric mixture with a wide antibacterial spectrum of activity ${ }^{(1,2)}$. The drug is the subject of a monograph in United States pharmacopoeia, USP $27^{(3)}$. Some methods have been

${ }^{\# \text { Corresponding author. E-mail address: fatmagawad@gmail.com }}$ 
reported for determination of cefprozil viz., chromatography ${ }^{(4,5)}$, flow-injection chemiluminescent $^{(6)}$ and spectrophotometry ${ }^{(7-10)}$. Saleh et al. ${ }^{(9)}$ used chloranilic acid for determination of phenolic $\beta$-lactam antibiotics including cefprozil and the color formed is determined spectrophotometrically. This method is used as a reference method for validation of the proposed methods.

Cefprozil:<smiles>C=CC1=C(C(=O)O)N2C(=O)C(NC(=O)C(N)c3ccc(O)cc3)C2SC1</smiles><smiles>CC=CC1=C(C(=O)O)N2C(=O)C(NC(=O)C(N)=C3C=CC(=O)C=C3)C2SC1</smiles>

Tizanidine:

2<smiles>Clc1ccc2nsnc2c1NC1=NCCN1</smiles>

2

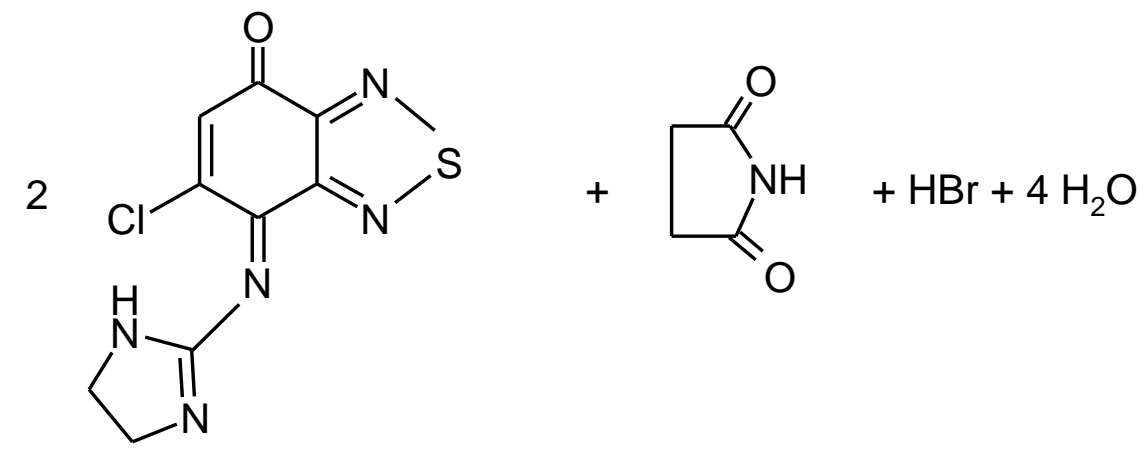<smiles>O=C1CCC(=O)N1Br</smiles><smiles>[13CH3]</smiles>

Scheme 1. Reaction of cefprozil and tizanidine with NBS in alkaline medium.

Egypt. J. Chem. 53, No. 1 (2010) 
Dropropizine, 3-(4-phenyl-1-piperazinyl)-1,2-propanediol (Scheme 2) is a cough suppressant reported to have a peripheral action in non-productive $\operatorname{cough}^{(11)}$. The drug is listed in Clark's, Analysis of Drugs and Poisons ${ }^{(12)}$. Studies on the human metabolism and the toxicological detection of the cough suppressant dropropizine in urine ${ }^{(13,14)}$ and plasma $^{(15)}$ using gas chromatographic-mass spectrometric methods are described.

Tizanidine, 5. chloro-4- (2- imidazolin -2-ylamino) -2, 1, 3- benzothiadiazole (Scheme 1) is $\alpha_{2}$-adrenergic agonist and centerally active myotonolytic skeletal muscle relaxant intended for the symptomatic treatment of acute muscle spasms and of chronic spasticity ${ }^{(11)}$. Some methods have been reported, including chromatography ${ }^{(16-22)}$, electrochemically ${ }^{(23,24)}$ and potentiometry using ion selective electrodes ${ }^{(25)}$.

Cefprozil:<smiles>C=CCC1=C(C(=O)O)N2C(=O)C(NC(=O)C(N)c3ccc(O)cc3)C2SC1</smiles><smiles>CC=CC1=C(C(=O)O)N2C(=O)C(NC(=O)C(N)c3cc(Br)c(O)c(Br)c3)C2SC1</smiles><smiles>O=C1CCC(=O)N1PBr</smiles>

Dropropizine:

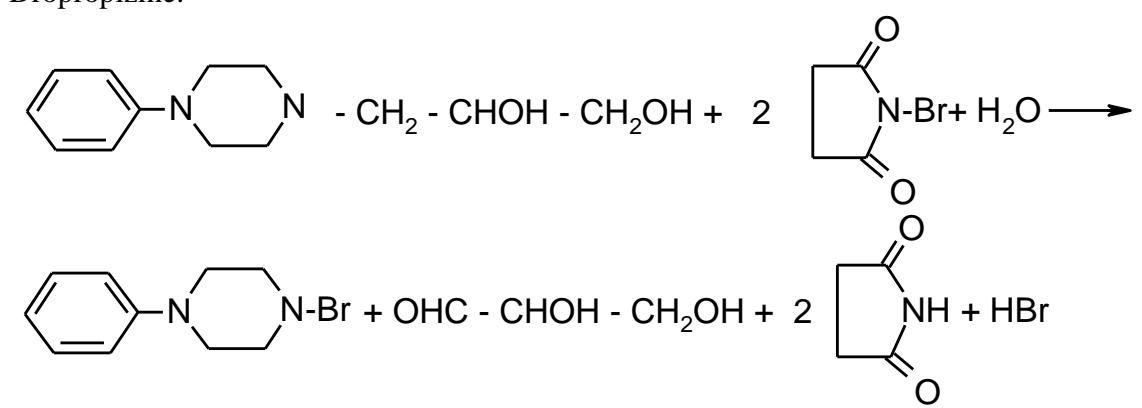

Scheme 2. Reaction of cefprozil and dropropizine with NBS in acidic medium.

NBS, being the most versatile, has been used for the spectrophotometric determination of different drugs ${ }^{(26-29)}$. These methods involves two stages oxidation of the drug by NBS and the estimation of unconsumed NBS with Celestine blue (CB). Some drugs can be directly determined with NBS in 
acidic $^{(30,31)}$ or alkaline ${ }^{(32-35)}$ media and the color formed is determined spectrophotometrically. Potentiometric method involves the direct titration of drug with NBS in acidic medium is rare in the literature ${ }^{(36)}$.

The main objective of this study is to find fast, accurate and sensitive spectrophotometric and potentiometric methods for the determination of cefprozil, dropropizine and tizanidine in their pure forms and in pharmaceutical preparations. The mechanism of oxidation of cefprozil and tizanidine with NBS in alkaline medium or cefprozil and dropropizine with NBS in acidic medium is suggested in order to throw more light on the nature of the oxidation product formed.

\section{Experimental}

\section{Apparatus}

A Shimadzu UV-visible 1601 spectrophotometer with quartz cells of 1-cm optical path length and HI 9321 Hanna Microprocessor $\mathrm{mV} / \mathrm{pH}$ meter with a combined platinum-saturated calomel electrode were used.

\section{Materials and reagents}

All chemicals were of analytical grade and all of the solutions were prepared with double distilled water. The following reagents were used, Nbromosuccinimide (Aldrich, $0.05 \%$ and $2 \times 10^{-3} \mathrm{M}$ ) aqueous solutions were prepared fresh dialy and standardized by an iodimetric method ${ }^{(37)}$. A $0.5 \mathrm{M}$ sodium hydroxide solution and $2.0 \mathrm{M}$ solutions of sulphuric, hydrochloric and acetic acids (BDH, UK) were prepared in distilled water. Methanol, ethanol, 2propanol, acetone, dimethylformamide (DMF) and dimethylsulphoxide (DMSO) were of HPLC grade and were directly used as supplied.

Anhydrous cefprozil, dropropizine and tizanidine hydrochloride were of pharmaceutical grade, anhydrous cefprozil (Bristol-Myers Squibb, USA), dropropizine (Eva Pharma, Cairo, Egypt) and tizanidine hydrochloride (Novartis Pharma AG Basle, Switzerland).

\section{Pharmaceutical preparations}

Cefzil tablets or powder for oral suspension (Squibb Co., Egypt) each labeled to contain $250 \mathrm{mg}$ of anhydrous cefprozil per tablet or $125 \mathrm{mg}$ per $5 \mathrm{ml}$ of oral suspension, Tussipine Lozenges (Eva Pharma, Egypt) labeled to contain $20 \mathrm{mg}$ of dropropizine per lozenge and Sirdalud tablets (Novartis Pharma, Egypt) labeled to contain $4 \mathrm{mg}$ of tizanidine hydrochloride per tablet were obtained from commercial sources.

\section{Preparation of standard solutions}

Anhydrous cefprozil, dropropizine and tizanidine hydrochloride solutions were prepared by dissolving $40 \mathrm{mg}$ of each drug in water or methanol. The solution was diluted with the same solvent to $100 \mathrm{ml}$ in a calibrated flask. Another solution of $10^{-2} \mathrm{M}$ of drug was prepared in water. The stock solutions of drugs were stable for at least 7 days when kept in the refrigerator (at about $4^{\circ} \mathrm{C}$ ). Whenever required dilute solutions were obtained by further dilution with the appropriate solvent.

Egypt. J. Chem. 53, No. 1 (2010) 
General procedures

Spectrophotometric method

In $10-\mathrm{ml}$ calibrated flasks, place $0.1-1.0 \mathrm{ml}$ or $0.2-2.0 \mathrm{ml}$ of $400 \mu \mathrm{g} \mathrm{ml}^{-1}$ for cefprozil or tizanidine standard methanolic solution, respectively, following by $1.0 \mathrm{ml}$ of $0.1 \mathrm{M}$ sodium hydroxide and $1.0 \mathrm{ml}$ of NBS $(0.05 \%)$ solutions. Mix well, complete to volume with methanol and measure the absorbance within 40 min at 396 and $384 \mathrm{~nm}$ for cefprozil and tizanidine, respectively, against a blank solution prepared similarly.

\section{Potentiometric method}

Volumes containing $0.13-1.30 \mathrm{mg}$ of cefprozil and $0.118-1.180 \mathrm{mg}$ of dropropizine, $1.0 \mathrm{ml}$ and $2.0 \mathrm{ml}$ of $2 \mathrm{M} \mathrm{H}_{2} \mathrm{SO}_{4}$ were added dropwisely, respectively, and the volume was completed to $25 \mathrm{ml}$ with bidistilled water. The Pt electrode was immersed in the solution and the titration was carried out potentiometrically using $2 \times 10^{-3} \mathrm{M}$ NBS solution as titrant from the microburette. The amount of NBS solution equivalent to the reacted drug solution was calculated.

\section{Analysis of tablets and lozenges}

Ten tablets or lozenges were weighed and finely grounded. A weighed amount of the fine powder equivalent to $40 \mathrm{mg}$ of pure drug was dissolved in $25 \mathrm{ml}$ of methanol for cefprozil or in dichloromethane for dropropizine and tizanidine. Stirred for 10 min and filtered through a Whatman No. 42 filter paper. The residue was washed well with the same solvent. The filtrate and washings were evaporated to dryness under vacuum and the left drug was dissolved in water (potentiometric method) or methanol (spectrophotometric method), and diluted to $100 \mathrm{ml}$ with the same solvent. Whereas solution of cefprozil in methanol is directly completed to $100 \mathrm{ml}$ with methanol, for spectrophotometric method. Dilute solution if necessary and analyse the resulting solution as described under General procedures.

Analysis of powder for oral suspension

In a $100 \mathrm{ml}$ conical flask, place a quantity of oral suspension powder equivalent to $40 \mathrm{mg}$ of anhydrous cefprozil and dissolve in $25 \mathrm{ml}$ of methanol. Complete the procedure as directed under Analysis of tablets and lozenges.

\section{Results and Discussion}

\section{Spectrophotometric method}

The method is based on the selective oxidation of cefprozil and tizanidine with NBS in an alkaline medium to give an intense yellow product with a maximum absorption at 396 and $384 \mathrm{~nm}$, respectively. The spectrophotometric properties of the colored species as well as the influence of different parameters on the color development were studied to determine optimum conditions of the assay procedure. The course of the reaction has been studied as a function of concentration of reagent, type and concentration of alkali and diluting solvents. In addition, the molar ratio of reactants and the stability of colored formed were determined. N.B. Such color was not observed on carrying out the same reaction 
with dropropizine. The color developed immediately (within few seconds) and remained stable for $40 \mathrm{~min}$ for the two drugs with NBS.

Investigating the color formation, using 40 or $80 \mathrm{ug} \mathrm{ml}^{-1}$ for cefprozil or tizanidine, respectively, it was found that maximum absorbance readings were obtained when $0.8-1.2 \mathrm{ml}$ of $0.05 \%$ NBS solution was used in a total volume of $10 \mathrm{ml}$. Increasing the NBS concentration would decrease the absorbance of the color formation. One $\mathrm{ml}$ of $0.05 \%$ NBS was chosen for two drugs to carry out the other studies.

In acid and neutral media, no development of color was observed, whereas in an alkaline, the yellow color developed immediately. Different alkalies were tested as: sodium hydroxide, ammonium hydroxide, sodium carbonate, sodium hydrogen carbonate and sodium acetate. Sodium hydroxide was found to be the most suitable, due to the higher sensitivity and more stability of the color. It is found that $1.0 \mathrm{ml}$ of $0.1 \mathrm{M} \mathrm{NaOH}$ is more suitable for carrying out this method. The reagent must be added directly after the addition of sodium hydroxide. Water, methanol, ethanol, 2propanol, acetone, dimethylformamide (DMF) and dimethylsulphoxide (DMSO) were tested as diluting solvents. The results obtained revealed that methanol and ethanol were the best solvents for the procedure.

\section{Molar ratio of reactants}

Application of Job's method of continuous variation ${ }^{(38)}$ using equimolar solutions of cefprozil or tizanidine and NBS in varying proportions while keeping the total molar concentration constant $\left(2 \times 10^{-4} \mathrm{M}\right)$. The plot of the absorbance of these solutions versus the mole fraction of the drug is represented graphically in Fig. 1. The results show the formation of $1: 2$ or $2: 1$ (drug: NBS) for cefprozil or tizanidine, respectively.

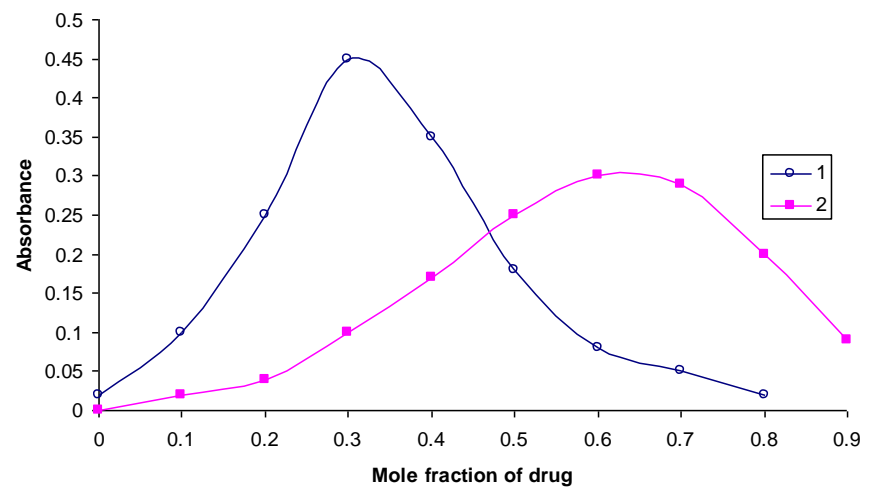

Fig.1. Continuous variation plots for oxidation of: (1) cefprozil, $\lambda=396 \mathrm{~nm}$ and (2) tizanidine, $\lambda=384 \mathrm{~nm}$ with NBS in alkaline medium. Total molar concentration $=2 \times 10^{-4} \mathrm{M}$.

\section{Reaction mechanism in alkaline medium}

The reaction of cefprozil with NBS in alkaline medium is reported to be an oxidation process which consists of the generation of free phenoxy radical which Egypt. J. Chem. 53, No. 1 (2010) 
can be stabilized by the formation of a quinone through the delocalization of the unpaired electrons over the aromatic ring of cefprozil ${ }^{(39)}$.

Likwise, it may be inferred that the oxidation of tizanidine occurred at the secondary nitrogen with possible formation of a quinoneimine structure ${ }^{(23)}$. The latter structure had been suspected as a possible metabolite in animal and man ${ }^{(40)}$. Scheme 1 shows a proposed mechanism for the reaction between cefprozil or tizanidine and $\mathrm{NBS}$ in $\mathrm{NaOH}$ solution at room temperature $\left(25^{\circ} \mathrm{C}\right)$.

\section{Analytical parameters}

Under the experimental condition described above, Beer's law was verified and was found to be satisfactory in the concentration range 5-40 and 10-80 $\mu \mathrm{g} \mathrm{ml}^{-1}$ for cefprozil and tizanidine hydrochloride, respectively. The molar absorptivities, Sandell sensitivities and the regression equations were included in Table 1 . The intercepts of the lines were very small indicating that there is no systematic differences between determined and expected concentration within the investigated concentration range using this method. For more accurate results, Ringbom ${ }^{(41)}$ concentration range was determined and represented in Table 1. LOD and LOQ are also calculated and listed in Table 1.

TABLE 1. Analytical parameters for determination of cefprozil and tizanidine hydrochloride in pure form by applying NBS reagent in $0.01 \mathrm{M} \mathrm{NaOH}$.

\begin{tabular}{lcc}
\hline Parameters & Cefprozil & Tizanidine. HCl \\
\hline$\lambda$ max, $\mathrm{nm}$ & 396 & 384 \\
Beer's law limits $\left(\mu \mathrm{g} \mathrm{ml}^{-1}\right)$ & $5-40$ & $10-80$ \\
Ringbom optimum concentration range $\left(\mu \mathrm{g} \mathrm{ml}^{-1}\right)$ & $10-40$ & $17-80$ \\
Molar absorptivity $\left(1 \mathrm{~mol}^{-1} \mathrm{~cm}^{-1}\right)$ & $8.57 \times 10^{3}$ & $2.83 \times 10^{3}$ \\
Sandell sensitivity $\left(\mu \mathrm{g} \mathrm{cm}^{-2}\right)$ & 0.045 & 0.102 \\
Slope $(\mathrm{b})$, specific absorptivity & 0.022 & 0.0097 \\
$\mathrm{~S}_{\mathrm{b}}(\mathrm{SD}$ of slope) & 0.013 & 0.006 \\
Intercept(a) & 0.003 & 0.003 \\
$\mathrm{~S}_{\mathrm{a}}(\mathrm{SD}$ of intercept) & 0.312 & 0.237 \\
$\mathrm{~S}_{\mathrm{y} / \mathrm{x}}(\mathrm{SD}$ of residuals) & 0.364 & 0.177 \\
Correlation coefficient $(\mathrm{r})$ & 0.9999 & 0.9998 \\
Relative standard deviation $(\%, \mathrm{n}=5)$ & 0.30 & 0.34 \\
LOD $\left(\mu \mathrm{g} \mathrm{ml}{ }^{-1}\right)$ & 0.41 & 1.08 \\
LOQ $\left(\mu \mathrm{g} \mathrm{m}{ }^{-1}\right)$ & 1.36 & 3.61 \\
\hline
\end{tabular}

Regression equation: $\mathrm{A}=\mathrm{a}+\mathrm{bC}$, where $\mathrm{A}=$ absorbance , $\mathrm{C}=$ concentration of drug.

In order to determine the accuracy and precision of the method, solutions containing three different concentrations of cefprozil or tizanidine were prepared and five replicate determinations were carried out for the pure form of the drugs under investigation. The relative standard deviation (RSD) and the standard analytical error (SAE) are small (Table 2), indicating the accuracy and precision of the present method. The correlation coefficients were 0.9999 and 0.9998 for cefprozil and tizanidine, respectively, indicating good linearity of the proposed method (Table 1). 
TABLE 2. Tests on precision of the spectrophotometric method on samples of pure drugs (cefprozil and tizanidine hydrochloride).

\begin{tabular}{|c|c|c|c|c|c|}
\hline Sample & $\begin{array}{c}\text { Taken } \\
\left(\mu \mathrm{g} \mathrm{ml}^{-1}\right)\end{array}$ & Found \pm SD $^{a}$ & SAE & $\begin{array}{c}\text { Recovery } \\
(\%) \\
\end{array}$ & $\begin{array}{r}\text { RSD } \\
(\%) \\
\end{array}$ \\
\hline \multirow{4}{*}{ Cefprozil } & 12.5 & $12.43 \pm 0.11$ & 0.049 & 99.44 & 0.88 \\
\hline & 25.0 & $24.93 \pm 0.08$ & 0.036 & 99.72 & 0.32 \\
\hline & 35.0 & $34.88 \pm 0.18$ & 0.081 & 99.66 & 0.52 \\
\hline & Mean & & 0.055 & 99.61 & 0.57 \\
\hline Tizanidine. & 25 & $24.65 \pm 0.08$ & 0.036 & 98.60 & 0.32 \\
\hline \multirow[t]{3}{*}{$\mathrm{HCl}$} & 35 & $35.22 \pm 0.05$ & 0.022 & 100.63 & 0.14 \\
\hline & 50 & $49.90 \pm 0.11$ & 0.049 & 99.80 & 0.22 \\
\hline & Mean & & 0.036 & 99.68 & 0.23 \\
\hline
\end{tabular}

${ }^{a}$ Mean \pm standard deviation of five determinations.

$\mathrm{RSD}=$ relative standard deviation.

$\mathrm{SAE}=$ standard analytical error $=\mathrm{SD} / \sqrt{N}$.

\section{Potentiometric method}

This part of work describes the use of NBS as titrant in the potentiometric determination of cefprozil and dropropizine in an acidic medium. However, this method failed for determination of tizanidine hydrochloride in acidic medium, due to the fluctuation of the end point from the expected value. The reaction conditions were studied extensively and the molar ratio of the reactants was calculated. The reaction mechanism was also included.

The effect of acids such as sulphuric, hydrochloric and acetic acids on the quantitative reaction between cefprozil or dropropizine and NBS is studied at a suitable ratio of [drug]: [NBS] of $1: 2$. The results show a charp end point on using sulphuric acid more than hydrochloric and acetic acids. The studies revealed that 1.0 and $2.0 \mathrm{ml}$ of $2 \mathrm{M} \mathrm{H}_{2} \mathrm{SO}_{4}$ are suitable for the determination of cefprozil and dropropizine, respectively, in the total volume of $25 \mathrm{ml}$. The amount of $\mathrm{H}_{2} \mathrm{SO}_{4}$ acts as $\mathrm{H}^{+}$donor and works as supporting electrolyte to keep the ionic strength constant during the titration process. The optimum concentration of NBS is $2 \times 10^{-3} \mathrm{M}$ to achieve constant and highly stable potential readings within 1-2 min of mixing. Raising the temperature does not accelerate the oxidation process and tends to cause inaccurate results and creates difficulty in detecting the end point because of decomposition of NBS at higher temperature. Then, room temperature $\left(25 \pm 1{ }^{\circ} \mathrm{C}\right)$ is the most suitable for the potentiometric titrations.

\section{Stoichiometric reaction}

As shown in Fig. 2, it is confirmed that 3 or 2 moles of NBS were required for complete bromination and oxidation of each mole of cefprozil or dropropizine, respectively, and as illustrated in Scheme 2. 

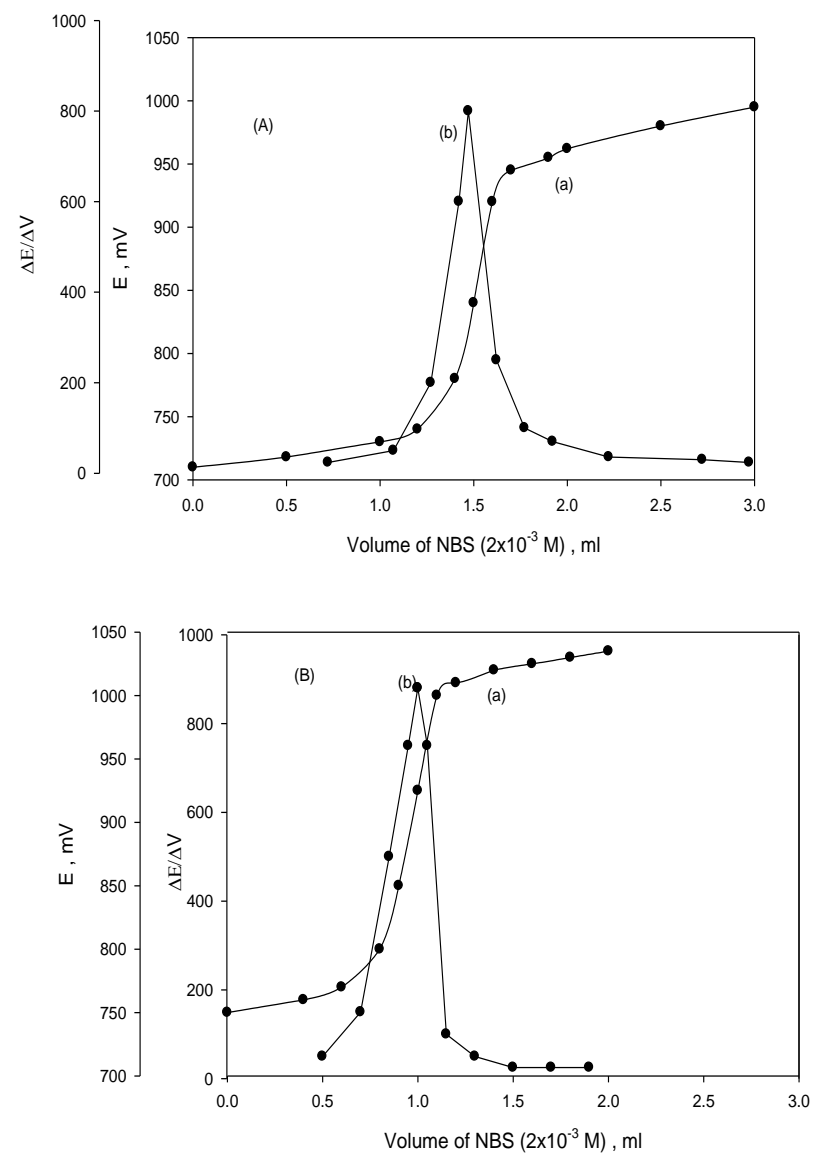

Fig. 2. Potentiometric titration curves for: (A) cefprozil $\left(1.0 \mathrm{ml}\right.$ of $\left.10^{-3} \mathrm{M}\right)$ and (B) dropropizine (1.0 $\mathrm{ml}$ of $10^{-3} \mathrm{M}$ ) (a) using Pt-electrode, (b) their differential curves.

\section{Reaction mechanism in acidic medium}

It is reported to mention here that bromination of phenols is expected to occur only in acidic medium ${ }^{(37)}$. The bromination and oxidation of cefprozil with $\mathrm{NBS}$ in $\mathrm{H}_{2} \mathrm{SO}_{4}$ medium can be postulated in Scheme 2. This indicates that the phenolic-OH group in the para position, which activates the ring for electrophilic substitution. Then the bromination of phenolic-OH results in the formation of the dibromo derivatives in the two ortho positions to the phenolic-OH group ${ }^{(39)}$.

Moreover, the characteristic maximum absorption for cefprozil in sulphuric acid medium appears at $297 \mathrm{~nm}$, due to the $\beta$-lactam ring of cefprozil, which shifted to $253 \mathrm{~nm}$ when added NBS. This indicates that the $\beta$-lactam ring includes in the oxidation of cefprozil through the tertiary amine in the $\beta$-lactam ring. Then the suggested mechanism of the oxidation reaction product of cefprozil is illustrated in Scheme 2. 
In case of dropropizine compound, the oxidation reaction can be explained that $\mathrm{N}$-substituted piperazine group, owing to its basicity, nitrogen atom is the side of the reaction with organic brominating agents ${ }^{(42)}$. The reaction mechanism was proposed and given in Scheme 2. NBS reacts readily and quantitatively with aqueous solutions of cefprozil and dropropizine, being itself reduced to succinimide, with the liberation of hydrobromic acid (Scheme 2).

\section{Potentiometric titration of drug}

The titration curves of drugs show one well-defined S-chaped stiochiometric end point using a Pt-electrode as an indicator electrode. The titration curves are given in Fig. 2 (as example), which represent the plot of E vs. volume (ml) of titrant. The first differential curves which represent the plot of $\Delta \mathrm{E} / \Delta \mathrm{v}$ vs. mean volume of titrant, are characterized by sharp inflection lying in the immediate vicinity of the expected end points. This shape inflection permits the accurate determination of the end point, and found that $1.0 \mathrm{ml}$ of $2 \times 10^{-3} \mathrm{M} \mathrm{NBS}$ is equivalent to $0.26 \mathrm{mg}$ of cefprozil or $0.236 \mathrm{mg}$ of dropropizine.

The results of the drug determination presented in Table 3 showed that good recoveries and low relative standard deviations were obtained. In order to establish whether the proposed method exhibits any fixed or proportional bais, a simple linear regression $^{(43)}$ of observed drug concentration against the theoretical values was calculated. The calculated t-values are 0.08 and 0.37 for cefprozil and dropropizine, respectively, which are lower than the tabulated value at $95 \%$ confidence level and four degrees of freedom (2.776). Thus there are no systematic differences between the determined and the true concentration over a wide range of 0.13-1.30 or $0.118-1.180 \mathrm{mg}$ for cefprozil or dropropizine, respectively.

TABLE 3. Potentiometric determination of cefprozil and dropropizine in pure solutions with NBS $\left(2.0 \times 10^{-3} \mathrm{M}\right)$.

\begin{tabular}{ccccc}
\hline $\begin{array}{c}\text { Taken } \\
(\mathbf{m g})\end{array}$ & $\begin{array}{c}\text { Found }^{\mathbf{a}} \\
(\mathbf{m g})\end{array}$ & Recovery $(\boldsymbol{\%})$ & $\begin{array}{c}\text { RSD } \\
(\boldsymbol{\%})\end{array}$ & $\begin{array}{c}\text { SAE } \\
(\boldsymbol{\%})\end{array}$ \\
\hline $\begin{array}{c}\text { Cefprozil } \\
0.13\end{array}$ & 0.128 & 98.46 & 0.44 & 0.20 \\
0.52 & 0.524 & 100.77 & 0.54 & 0.24 \\
1.30 & 1.305 & 100.38 & 0.39 & 0.17 \\
Mean & & 99.87 & 0.46 & 0.20 \\
Dropropizine & & & & \\
0.118 & 0.119 & 100.85 & 0.87 & 0.39 \\
0.472 & 0.470 & 99.58 & 0.60 & 0.27 \\
1.180 & 1.186 & 100.51 & 0.52 & 0.23 \\
Mean & & 100.31 & 0.66 & 0.30 \\
\hline
\end{tabular}

${ }^{a}$ Average of five determinations. 
The accuracy of the proposed methods was also checked by performing recovery experiments using the standard addition method ${ }^{(44)}$. The results are grouped in Table 4. These results prove the accuracy of the proposed methods and absence of interference from the common excipients. The extraction of cefprozil with methanol from tablets or oral suspension and dropropizine or tizanidine hydrochloride with dichloromethane from lozenges or tablets, respectively, could eliminate the interference from the common excipients. The obtained good recoveries ensured the suitability of the methods for the analysis of cefprozil, dropropizine and tizanidine in their dosage forms without interference from the common excipients.

TABLE 4. Standard addition method for the determination of cefprozil, dropropizine and tizanidine hydrochloride by spectrophotometric and potentiometric methods.

\begin{tabular}{|c|c|c|c|}
\hline \multirow[b]{2}{*}{ Drug } & \multirow[b]{2}{*}{ Pharamecutical $^{\mathrm{a}}$} & \multicolumn{2}{|c|}{ Recovery \pm SD $(\%)^{b}$} \\
\hline & & $\begin{array}{c}\text { Spectrophotometric } \\
\text { method }\end{array}$ & $\begin{array}{c}\text { Potentiometric } \\
\text { method }\end{array}$ \\
\hline \multirow[t]{2}{*}{ Cefprozil } & $\begin{array}{c}\text { Cefzil tablets } \\
(250 \mathrm{mg} / \text { tablet })\end{array}$ & $99.82 \pm 0.46$ & $99.50 \pm 0.54$ \\
\hline & $\begin{array}{c}\text { Cefzil oral } \\
\text { suspension } \\
(125 \mathrm{mg} / 5 \mathrm{ml})\end{array}$ & $100.23 \pm 0.65$ & $100.12 \pm 0.73$ \\
\hline Dropropizine & $\begin{array}{c}\text { Tussipine lozenges } \\
\text { (20 mg / lozenge) }\end{array}$ & & $100.35 \pm 0.67$ \\
\hline Tizanidine. $\mathrm{HCl}$ & $\begin{array}{l}\text { Sirdalud tablets } \\
\text { (4 mg / tablet })\end{array}$ & $99.78 \pm 0.49$ & \\
\hline
\end{tabular}

${ }^{a}$ Amount taken from pharmaceutical preparations is equal to amount added from pure drugs $\left(20 \mathrm{ug} \mathrm{ml}^{-1}\right.$ and $0.5 \mathrm{mg}$ of pure drug for spectrophotometric and potentiometric methods, respectively).

${ }^{\mathrm{b}}$ Mean and standard deviation of five determinations.

Determination of the active components in pharmaceuticals

The proposed methods were successfully applied to determine cefprozil, dropropizine and tizanidine hydrochloride in their dosage forms. The results obtained were compared statistically by Student's t-test (for accuracy) and variance ratio F-test (for precision) with the reference methods ${ }^{(9,19)}$, at $95 \%$ confidence level with eight and four degrees of freedom for $\mathrm{t}$ - and F-tests, respectively, as shown in Table 5. The results showed that the $\mathrm{t}$ - and $\mathrm{F}$ - values were less than the critical values, indicating that there was no significant difference between the proposed and reference methods. The proposed methods were more accurate with high recoveries and low standard deviations, so the proposed methods can be recommended for routine analysis of drug alone and in its dosage forms without fear of interferences caused by the excipients expected to be present in tablets, lozenges or oral suspensions. 
TABLE 5. Application of the proposed methods for the determination of cefprozil, dropropizine and tizanidine hydrochloride in pharmaceutical preparations.

\begin{tabular}{|c|c|c|c|c|}
\hline \multirow[b]{2}{*}{ Drug } & \multirow[b]{2}{*}{ Pharamecutical } & \multicolumn{3}{|c|}{ Found \pm SD $(\%)^{\mathrm{a}}$} \\
\hline & & $\begin{array}{c}\text { Spectrophotometric } \\
\text { method }\end{array}$ & $\begin{array}{c}\text { Potentiometric } \\
\text { method }\end{array}$ & $\begin{array}{c}\text { Reference } \\
\text { method }\end{array}$ \\
\hline Cefprozil & $\begin{array}{c}\text { Cefzil tablets } \\
\text { (250 mg/ tablet) }\end{array}$ & $\begin{array}{c}100.26 \pm 0.67 \\
t=1.68 \\
F=1.97\end{array}$ & $\begin{array}{c}99.96 \pm 0.73 \\
t=1.07 \\
F=1.66\end{array}$ & $99.39 \pm 0.94[9]$ \\
\hline & $\begin{array}{c}\text { Cefzil oral } \\
\text { suspension } \\
(125 \mathrm{mg} / 5 \mathrm{ml})\end{array}$ & $\begin{array}{c}100.63 \pm 0.76 \\
t=0.94 \\
F=1.77\end{array}$ & $\begin{array}{c}100.52 \pm 0.80 \\
t=0.73 \\
F=1.59\end{array}$ & $100.10 \pm 1.01[9]$ \\
\hline Dropropizine & $\begin{array}{c}\text { Tussipine } \\
\text { lozenges } \\
\text { (20 mg/lozenge) }\end{array}$ & & $99.87 \pm 0.69$ & \\
\hline $\begin{array}{c}\text { Tizanidine. } \\
\mathrm{HCl}\end{array}$ & $\begin{array}{l}\text { Sirdalud tablets } \\
\text { (4 mg / tablet) }\end{array}$ & $\begin{array}{c}99.75 \pm 0.59 \\
t=0.32 \\
F=2.22\end{array}$ & & $\begin{array}{c}99.60 \pm 0.88[19] \\
(2.306)^{\mathrm{b}} \\
(6.39)^{\mathrm{b}}\end{array}$ \\
\hline
\end{tabular}

${ }^{\mathrm{a}}$ Mean and standard deviation of five determinations.

${ }^{\mathrm{b}}$ The tabulated values of $\mathrm{t}-$ and F-tests at $95 \%$ confidence limit.

\section{Conclusion}

The N-bromosuccinimide methods in this work for the quantitation of cefprozil, dropropizine and tizanidine hydrochloride are direct methods. The spectrophotometric method is accurate and more sensitive than the chloranilic acid method $^{(9)}$ used for the determination of cefprozil. Furthermore, the proposed methods do not need the elaborate treatment and tedious extractions required in chromatographic method ${ }^{(19)}$. The shapes of the potentiometric titration curves of pure drugs and the corresponding pharmaceuticals are nearly the same which proves that the excipients which might be present in the pharmaceutical preparations do not affect the titration curves. The data given above reveals that the proposed methods are accurate and sensitive with good precision and accuracy. With these methods, one can do the analysis of these drugs at low cost without losing accuracy. The proposed methods are quite suitable for routine quality control analysis of pharmaceutical preparations.

\section{References}

1. Remers, W.A. and Delagado, J.N., Wilson and Gisfold's Text-book of Organic Medicinal and Pharmaceutical Chemistry, $10^{\text {th }}$ ed. pp. 274-290, Lippincott-Raven Publishers, Philadelphia, NY (1998).

2. Sader, H.S., Jacobs, M.R. and Fritsche, T.R., Diagn. Microbial. Infect. Dis. 57, 5s (2007).

3. The United States Pharmacopoeia 27 National Formulary 22, Asian ed., Rand Mc Nally, USP Convention pp. 379-380 (2004).

Egypt. J. Chem. 53, No. 1 (2010) 
4. Park, T.H., Kim, J.K., Jee, J.P., Park, J.S. and Kim, C.K., J. Pharm. Biomed. Anal. 36, 243 (2004).

5. Le, J. and Hong, Z.Y., Yaowu Fenxi Zazhi, 24, 153 (2004).

6. Alarfaj, N.A. and Abd El-Razeq, S.A., J. Pharm. Biomed. Anal. 41, 1423 (2006).

7. Salem, H., Anal. Chim. Acta, 515, 333 (2004).

8. Salem, H. and Saleh, G.A., J. Pharm. Biomed. Anal. 28, 1205 (2002).

9. Saleh, G.A., Darwish, I.A. and El-Shourbagi, A.N.A., Anal. Sci. 19, 281 (2003).

10. Daabees, H.G., Mahrous, M.S., Abdel-Khalek, M.M., Beltagy, Y.A. and Emil, K.N., Anal. Lett. 34, 1639 (2001).

11. Martindale, The Extra Pharmacopoeia, $33^{\text {rd }}$. ed., pp. 1119, 1395, Pharmaceutical Press, London, UK (2002).

12. Clark's, Analysis of Drugs and Poisons, $3^{\text {rd }}$. ed., p. 964, Pharmaceutical press, London, UK (2004).

13. Staack, R.F. and Maurer, H.H., J. Chromatogr. B 798, 333 (2003).

14. Staack, R.F., Theobald, D.S. and Maurer, H.H., Ther. Drug Monit. 26, (2004).

15. Zaratin, P., De-Angelis, L. and Cattabeni, F., Arzneim-Forsch, 38, 1156 (1988).

16. Kaul, N., Dhaneshwar, S.R., Agrawal, H., Kakad, A. and Patil, B., J. Pharm. Biomed. Anal. 37, 27 (2005).

17. Gandhimathi, M., Ravi, T.K. and Varghese, S.J., J. Pharm. Biomed. Anal. 37, 183 (2005).

18. Mahadik, K.R., Paradkar, A.R., Agrawal, H. and Kaul, N., J. Pharm. Biomed.Anal. 33, 545 (2003).

19. Qi, M.L., Wang, P. and Wang, L., Anal. Chim. Acta, 478, 171 (2003).

20. Raman, B. and Patil, D., Indian Drugs, 39, 392 (2002).

21. Lee, L., Seo, J.H. and Kim, D.Y., Analyst, 127, 917 (2002).

22. Nirogi, S., Kandikere, V.N., Shukla, M., Mudigonda, K. and Maurya, S., Rapid Commun. Mass Spectrom. 20, 2286 (2006).

23. Kauffmann, J.M., Ruiz, B.L., Gotori, M.F. and Patriarche, G.J., J. Pharm. Biomed. Anal. 10, 763 (1992).

24. Tuncel, M. and Dogrukol, D., Anal. Lett. 25, 1087 (1992). 
25. Bouklouze, A.A., El-Jammal, A., Vire, J.C. and Patriarche, G.J., Anal. Chim. Acta, 257, 41 (1992).

26. Sastry, C.S.P., Naidu, P.Y. and Murty, S.S.N., Talanta, 44, 1211 (1997).

27. Sreedhar, K., Sastry, C.S.P., Reddy, M.N. and Sankar, D.G., Talanta, 43, 1847 (1996).

28. Lakshmi, C.S.R. and Reddy, M.N., Talanta, 47, 1279 (1998).

29. Amin, A.S., Ahmed, I.S., Dessouki, H.A. and Gouda, E.A., Spectrochim. Acta Part A 59, 695 (2003).

30. Rahman, N. and Asmi, S.N.H., Il Farmaco 59, 529 (2004).

31. Mohamed, A.I., Talanta, 44,1173 (1997).

32. Nagaraja, P., Murthy, K.C.S., Rangappa, K.S. and Gowda, N.M.M., Talanta, 46, 39 (1998).

33. Alwarthan, A.A. and Al-Obaid, A.M., J. Pharm. Biomed. Anal. 14, 579 (1996).

34. Pandey, S. and Upadhyay, S.K., J. Colloid Interface Sci. 285, 789 (2005).

35. Saleh, G.A., Analyst, 121, 641 (1996).

36. El-Ries, M.A., Mohamed, G., Khalil, S. and El-Shall, M., Chem. Pharm. Bull. (Japan) 51, 6 (2003).

37. Mathur, N.K. and Narang, C.K., The Determination of Organic Compounds with $N$ Bromosuccinimide and Allied Reagents, pp. 54-59, Academic Press, London, New York (1975).

38. Job, P., Ann. Chim. 9, 133 (1928).

39. Patai, S., The Chemistry of the Hydroxyl Group, p. 510 (Part 1),Wiley-Interscience, London, New York, Sydney, Toronto (1971).

40. Steckhan, E., In Organic Electrochemistry, H. Lund and M.M. Biazer Ed. pp. 581613, Marcel Dekker, New York (1991).

41. Ringbom, A., Z. Anal. Chem. 115, 332 (1939).

42. Walash, M.I., Risk, M., Abou-Ouf ,A. and Belal, F., Analyst, 108, 626 (1983).

43. Miller, J.C. and Miller, J.N., Statistics for Analytical Chemistry $2^{\text {nd }}$ ed. pp. 23-52 Ellis Horwood, Chichester (1988).

44. Ewing, G.W., Instrumental Methods of Chemical Analysis, $5^{\text {th }}$ ed., pp. 484-486, Lippincott-Raven, Philadelphia (1995). 


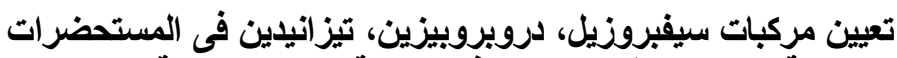

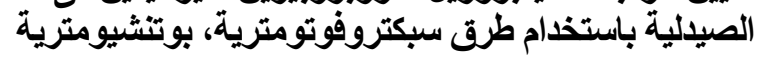

فاطمة محمد عبد الجواد ، كارمن شرابي مصطفى" ، صفاء محمد عبد الحميد

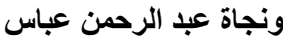

الهيئة القومية للرقابة و البحوث الدو الئية ـ الجيزة و *كلية العلوم - جامعة الأزهر -

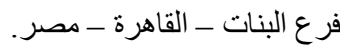

في هذا البحث تم استتباط طريقتين على درجة من الحساسية لتعبين بعض المركبات

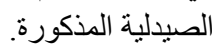

1- استخدام طريقة طيفية لتعيين السيفبروزيل، التيز انيدين و ذلك عن طريق أكسدة

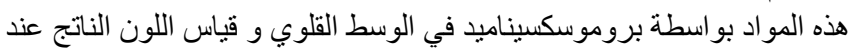

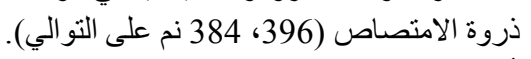

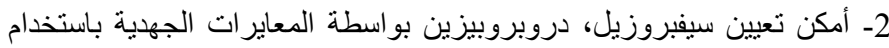

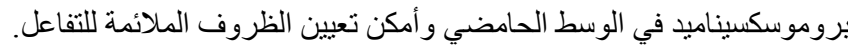

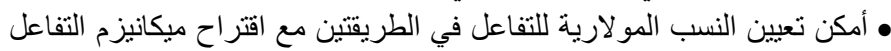

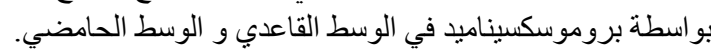

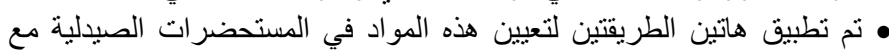

مقارنتها بطرق أخرى منشورة لهذه المواد و قد أعند العين نتائج جيدة. 